\title{
Complete washout of a colloid cyst on MRI after partial removal by endoscopic approach
}

\author{
Thomas Robert • Philippe Maeder • Marc Levivier • \\ Claudio Pollo
}

Received: 26 April 2011 / Accepted: 5 May 2011 /Published online: 25 May 2011

(C) Springer-Verlag 2011

\section{Dear Sir,}

We would like to bring to your attention a case of progressive disappearance of a colloid cyst after endoscopic resection of a minor portion of the lesion, as documented by magnetic resonance imaging (MRI).

This right-handed 50-year-old male presented with general fatigue associated with disturbance of concentration and intermittent headache. Clinical neurological examination was normal. A computed tomography (CT) and an MRI of the brain revealed a cystic lesion in the area of the foramen of Monro in the roof of the third ventricle. On CT, the lesion was hyperdense. On MRI, the lesion was hyperintense on T1-weighted images and hypointense on T2-weighted images. The cyst obstructed the foramen of Monro (Fig. 1) leading to hydrocephalus of both lateral ventricles.

Image-guided endoscopic removal of the lesion was performed through a right frontal approach under general

T. Robert $(\varangle) \cdot$ M. Levivier $\cdot$ C. Pollo

Department of Neurosurgery,

Centre Hospitalier Universitaire Vaudois,

Lausanne, Switzerland

e-mail: Thomas.robert43@gmail.com

P. Maeder

Department of Radiology,

Centre Hospitalier Universitaire Vaudois,

Lausanne, Switzerland anaesthesia (Fig. 2). Only a minor portion of the lesion was removed by the endoscopic approach considering the risk of traction on the fornix through the chosen trajectory. No complication occurred during surgery. Histological examination showed the typical aspect of a colloid cyst. A postoperative MRI, performed $48 \mathrm{~h}$ after the surgery, revealed only a slight decrease of the dimensions of the cyst (Fig. 3). There was a clear decrease in the size of the lateral ventricles, suggesting a better permeability of the foramen of Monro.

Postoperatively, the symptoms of the patient disappeared and he was discharged 5 days later. Postoperative MRIs performed at 3 months and every year until 4 years after surgery surprisingly revealed a progressive disappearance of the colloid cyst with complete permeability of the foramen of Monro (Fig. 4).

Third ventricular colloid cysts are rare benign lesions which are typically hyperintense on $\mathrm{T} 1$ and hypointense on T2-weighted MRI [1-9]. The correlation of the T1weighted MR imaging hyperintensity of the cyst and a high concentration of cholesterol in colloid cyst has been documented by Maeder et al. [7]. This was also confirmed in our patient at histological examination.

Although recurrence of colloid cysts after total removal is exceptional, the postoperative radiological follow-up of a partially removed lesion has not been reported in the literature $[5,6,10-12]$. Our case shows that even partial removal of a colloid cyst can result in total washout of the lesion without recurrence during a 4-year follow-up. 

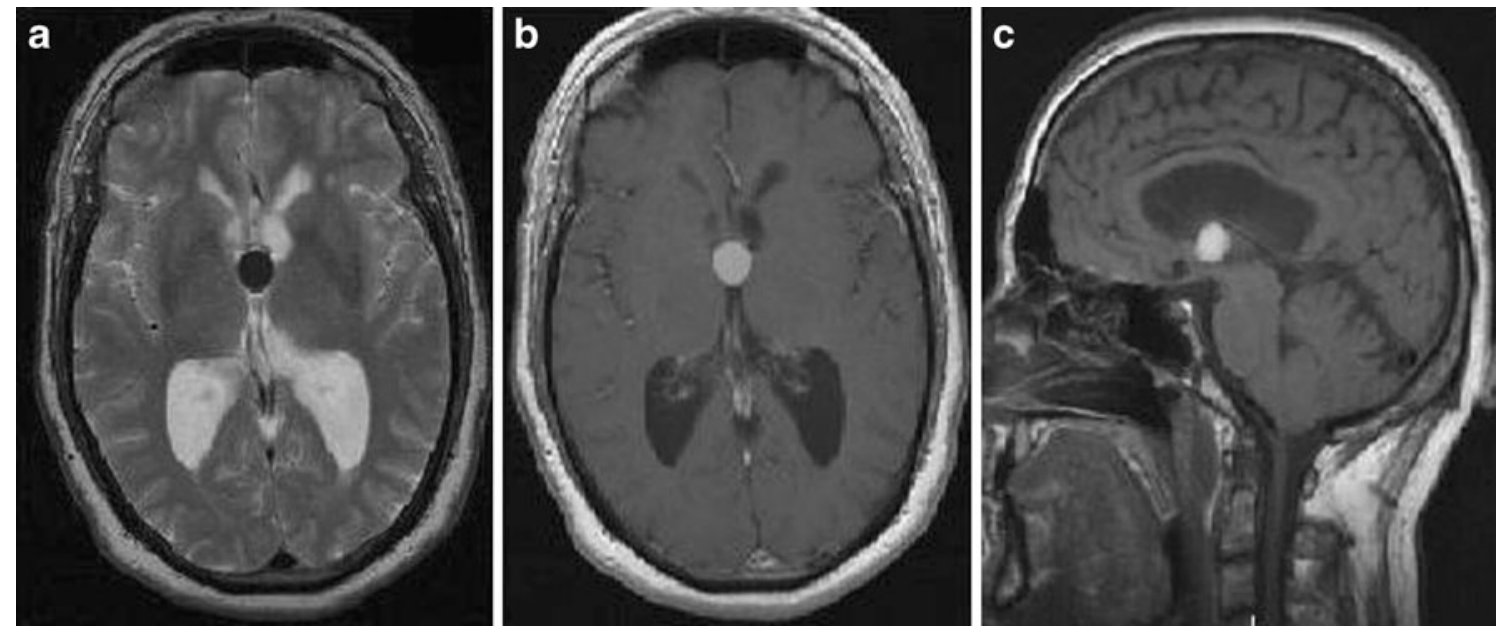

Fig. 1 Preoperative images. a Tranverse T2-weighted image, evidence of a lesion in the anterior part of the third ventricle with T2-hypointense aspect. b Tranverse and c sagittal T1-weighted images. The lesion is T1-hyperintense. Notice biventricular dilatation

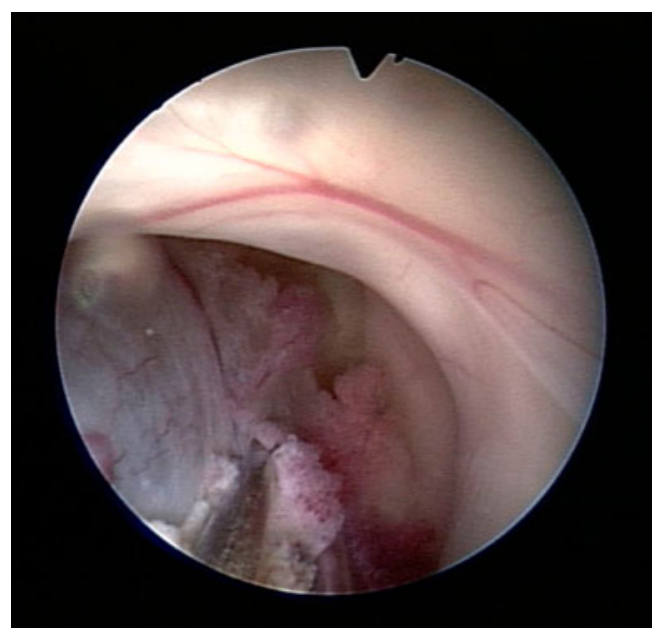

Fig. 2 Intraoperative photograph of the endoscopic approach
Further cases and series with longer follow-up should be reported in order to confirm our finding.

Although we have no clear explanation for the progressive disappearance of the lesion, as documented by MRI, the most probable hypothesis is the washout of the cyst content by cerebrospinal fluid (CSF) after the surgical interruption of the cyst wall. This could be based on the poor compatibility between hydrophilic CSF and the hydrophobic cholesterol-rich gelatinous content of the cyst [13-15].

In conclusion, our finding shows that partial removal of a colloid cyst may result in total radiological disappearance. Regular follow-up with MRI is recommended in order to document the progressive washout of the lesion, as well as to detect any possible recurrence.
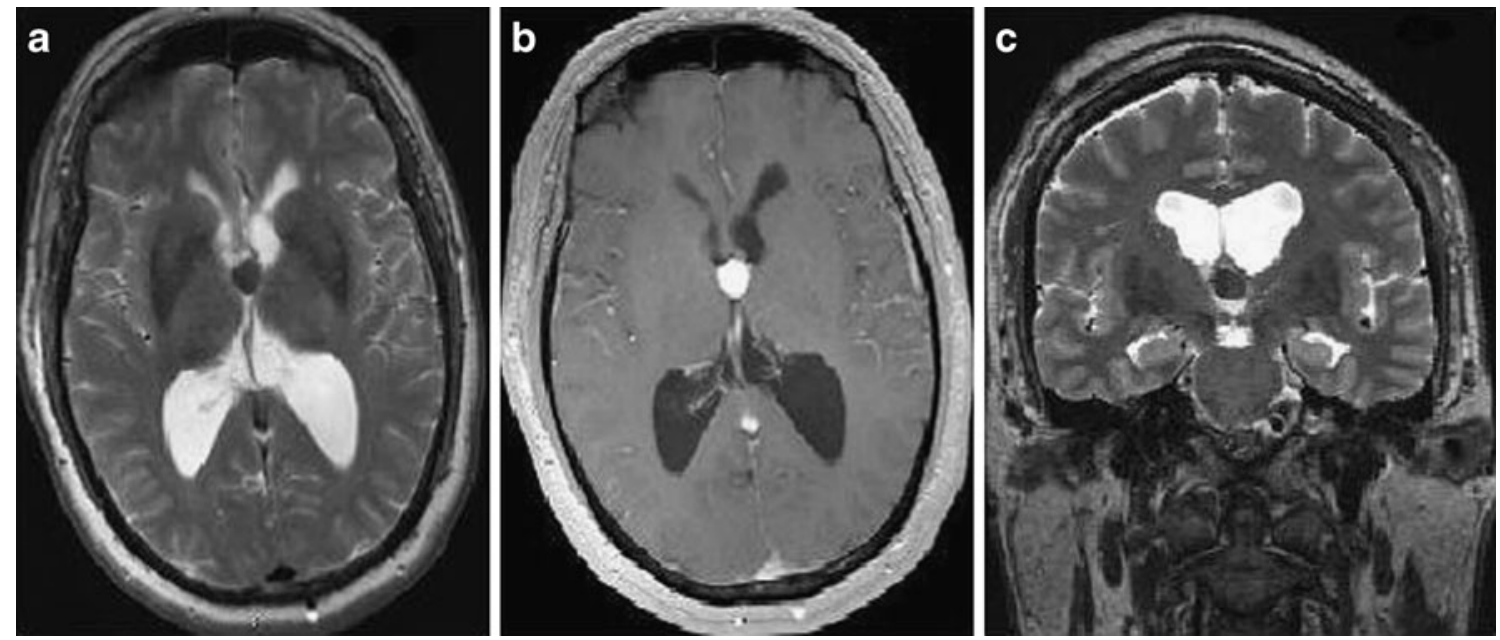

Fig. 3 Early postoperative MRI a transverse T2-weighted image, b transverse T1-weighted image and $\mathbf{c}$ coronal T2-weighted image. Notice the slight decrease in size of the colloid cyst and of both lateral ventricles 

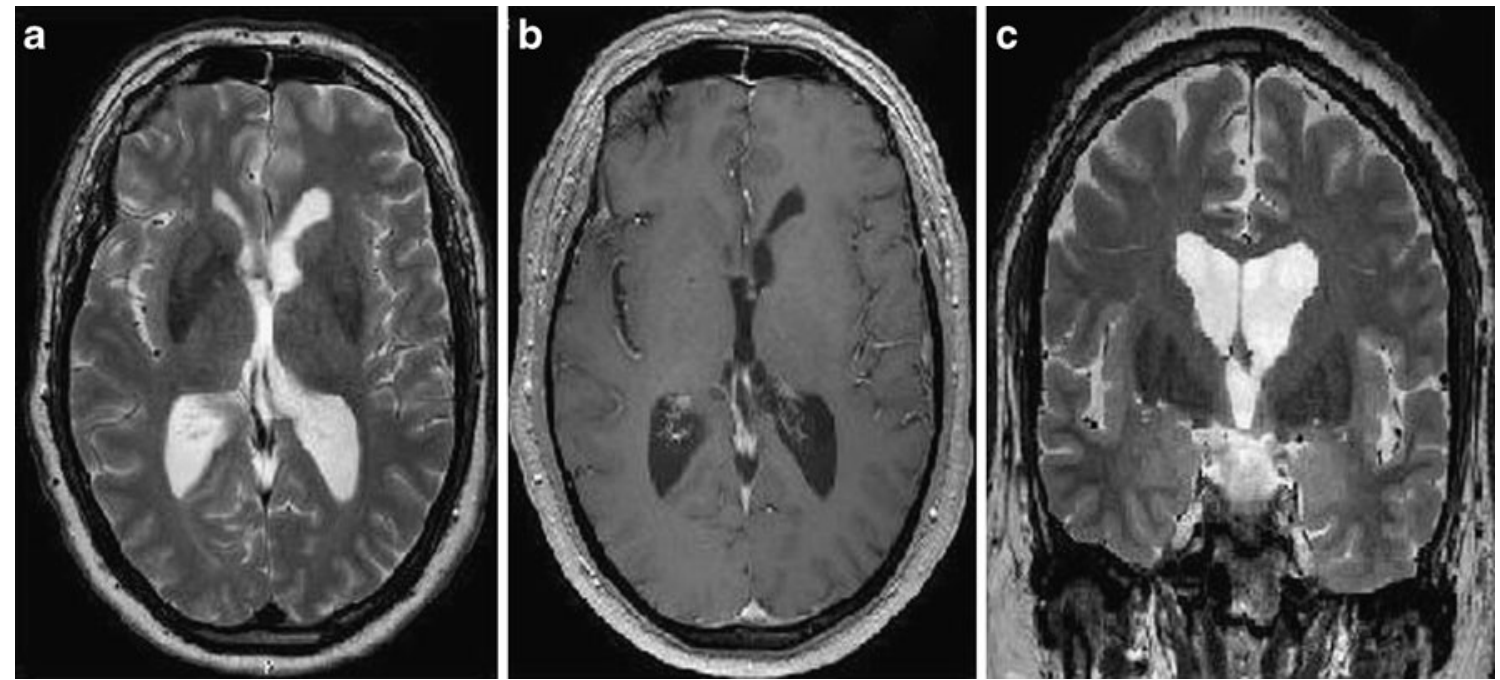

Fig. 4 Follow-up MRI at 24 months a transverse T2-weighted image, b transverse T1-weighted image and $\mathbf{c}$ coronal T2-weighted image. Notice the complete washout of the cyst and the restored permeability of the foramen of Monro

Conflict of interest We declare that we have no conflict of interest.

\section{References}

1. Levine NB, Miller MN, Crone KR (2007) Endoscopic resection of colloid cysts: indications, technique, and results during a 13-year period. Minim Invasive Neurosurg 50(6):313317

2. Grondin RT, Hader W, MacRay ME, Hamilton MG (2007) Endoscopic versus microsurgical resection of third ventricle colloid cysts. Can J Neurol Sci 34(2):197-207

3. Desai KI, Nadkarni TD, Muzumdar DP, Goel AH (2002) Surgical management of colloid cyst of the third ventricle - a study of 105 cases. Surgl Neurol 57(5):295-302

4. Ho KL, Garcia JH (1992) Colloid cysts of the third ventricle: ultrastructural features are compatible with endodermal derivation. Acta Neuropathol 83(6):605-612

5. Motoyama Y, Hashimoto H, Ishida Y, Iida J (2002) Spontaneous rupture of a presumed colloid cyst of the third ventricle - case report. Neurol Med Chir (Tokyo) 42(5):228-231

6. Horn EM, Feiz-Erfan I, Bristol RE, Lekovic GP, Goslar PW, Smith KA, Nakaji P, Spetzler RF (2007) Treatment options for third ventricular colloid cysts: comparison of open microsurgical versus endoscopic resection. Neurosurgery 60 (4):613-618
7. Maeder P, Holtas S, Nihal Basibuyuk L, Salford L, Staffan Tapper U, Brun A (1990) Colloid cyst of the third ventricle: correlation of MR and CT findings with histology and chemical analysis. AJNR Am J Neuroradiol 11(3):575-581

8. Sener RN (2007) Colloid cyst: diffusion MR imaging findings. J Neuroimaging 17(2):181-183

9. Shapiro S, Rodgers R, Shah M, Fulkerson D, Campbell R (2009) Interhemispheric transcallosal subchoroidal fornix-sparing craniotomy for total resection of colloid cysts of the third ventricle. $\mathrm{J}$ Neurosurg 110(1):112-115

10. Pollock BE, Schreiner SA, Huston J 3rd (2000) A theory of the natural history of colloid cyst. Neurosurgery 46(5):1077-1081

11. Poreh A, Winocur G, Moscovitch M, Backon M, Goshen E, Ram Z, Feldman Z (2006) Anterograde and retrograde amnesia in a person with bilateral fornix lesions following removal of a colloid cyst. Neuropsychologia 44(12):2241-2248

12. Schroeder HW, Oertel J, Gaab MR (2004) Incidence of complications in neuroendoscopic surgery. Childs Nerv Syst 20(11-12):878-883, Epub 2004 Jun 5

13. Bergsneider M (2007) Complete microsurgical resection of colloid cysts with a dual-port endoscopic technique. Neurosurgery 60 (2 Suppl 1):ONS33-ONS42, discussion ONS42-43

14. Greenlee JD, Teo C, Ghahreman A, Kwok B (2008) Purely endoscopic resection of colloid cysts. Neurosurgery 62(3 Suppl 1):51-55, discussion 55-56

15. Kondziolka D, Lundford LD (1992) Factors predicting successful stereotactic aspiration of colloid cysts. Stereotact Funct Neurosurg 59(1-4):135-138 